\title{
LITERATURA Y PODER: SOBRE LA POTENCIA DEL TESTIMONIO EN AMÉRICA LATINA
}

\author{
LITERATURE AND POWER: ON THE PRODUCTION \\ OF TESTIMONY IN LATIN AMERICA
}

\section{RAÚL RODRÍGUEZ FREIRE1}

\section{RESUMEN}

El objetivo principal es dar cuenta de la (in)utilidad de la definición de la narrativa testimonial, por un lado, y señalar que su emergencia data sólo de los años sesenta, por otro, de manera que la pretensión de buscar su genealogía en las crónicas coloniales y discursos afines es no entender su función. Finalmente, a partir de los escritos de Giorgio Agamben, propongo una manera distinta de leer la narrativa testimonial latinoamericana.

Palabras clave: Testimonio, archivo, verdad.

\section{ABSTRACT}

The primary objective of this paper is to give an account of the usefulness/uselessness of the definition of testimonial narrative, and to signal its origins or emergence dating from the nineteen sixties. On the other hand, I show that the pretension of seeking its genealogy in colonial chronicles and discourses is to misunderstand its function. Finally, from writings of Giorgio Agamben, I propose a different way to read Latin American testimonial narrative.

Keywords: Testimonio, archive, truth.

Recibido: 06.09.2007. Aprobado: 12.09.2008.

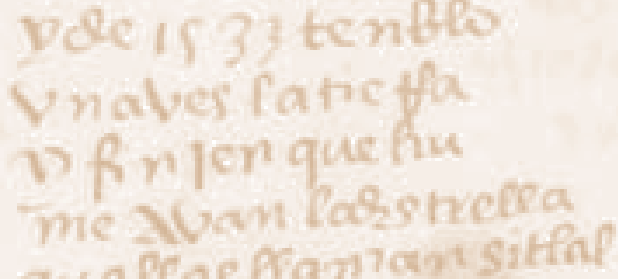

${ }^{1}$ Doctor (c) en Literatura, Universidad de Chile. Escuela de Historia, Facultad de Ciencias Sociales, Universidad Diego Portales, Santiago, Chile. E-mail rodriguezfreire@gmail.com 


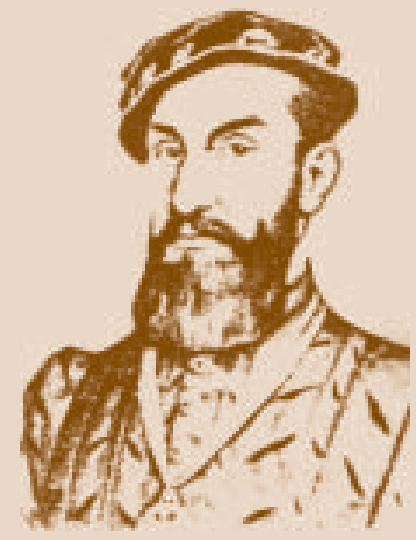

A. Núñez Cabeza de Vaca

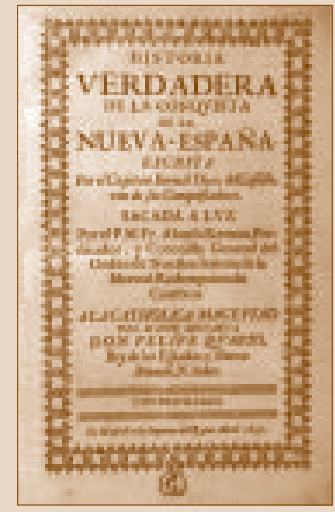

\section{PRESENTACIÓN}

$\mathrm{E}$ N EL CAMPO de la crítica literaria, y en la academia en general, la inquietud por ordenar y clasificar los discursos producidos a lo largo de la historia parecen ser una práctica bastante recurrente, e incluso casi definitoria para la enseñanza de los saberes institucionales. De ahí que la búsqueda de una "identidad" de "género discursivo" sea una actividad que también ha afectado a la narrativa testimonial, razón por la cual las crónicas, los testimonios e incluso las cartas producidas durante la época denominada "colonia" (e incluso antes de este periodo) han sido definidas por algunos y algunas intelectuales como el origen o el precedente de lo que hoy se conoce como narrativa testimonial. Otros, como Leonidas Morales, van más lejos al definir el testimonio como un discurso transhistórico, es decir, un tipo de discurso que, de acuerdo a Todorov, no es posible fijarlo en un único momento del tiempo, de manera que testimonio tenemos desde que la lengua existe. La pregunta que surge al respecto, y que guiará el desarrollo de este ensayo, es la siguiente: ¿existe relación alguna entre Naufragios, de Núñez Cabeza de Vaca (2001), la H istoria verdadera de la conquista dela Nueva España, de Bernal Díaz del Castillo (1983), el juicio inquisitorial a don Carlos Ometochtzin (en Lienhard, 1992:15-16), la H istoria general de las cosas de Nueva España, de Bernardino de Sahagún (1981), la Nueva crónica y buen gobierno, de Felipe Guaman Poma de Ayala (1980), los Comentarios reales, del Inca Garcilaso de la Vega (1999), la breve crónica (también llamada M emorial), de Titu Cusi Yupanqui (1973), las respuestas que realizaran los habitantes indígenas de Chucuito a las entrevistas que les aplicó en 1567 Garci Diez de San Miguel, por orden del gobernador de Perú ${ }^{2}$ (con el fin de averiguar de qué manera era posible aumentar la contribución fiscal a los gastos reales), las epístolas escritas por los letrados de las elites locales dirigidas al rey o aquellas otras formuladas por los sectores menos aventajados, tales como los municipios, también dirigidas al rey (en Lienhard, 1992), con textos contemporáneos tales como "Si mepermiten hablar..." testimonio de Domitila, una mujer de las minas de Bolivia (1988), M ellamo Rigoberta M enchú, y así menació la conciencia (1994), M ujeresen la Alborada de Yolanda Colom (2000), H ear my Testimony: M aría Teresa Tula, Human RightsActivist of El Salvador (1994), A puntes de una historia de amor que no fue, de Jacinta Escudos (1987), entre otros (pos supuesto, ninguna lista es exhaustiva)? Sí y no. Si la clasificación de los discursos -la identidad- es lo que se pretende,

\footnotetext{
${ }^{2}$ Ver Lienhard, 1992:17-21.
} 
estamos, entonces, obligados a incluir todos estos textos bajo la categoría denominada "género referencial", de manera que la respuesta sería Sí. Pero, cuando más que forzar una clasificación lo que se pretende es determinar las condiciones de emergencia del discurso testimonial para comprender sus implicancias sociopolíticas, la respuesta es $\mathrm{No}$, pues pertenecen cada uno a su contexto, ya que sus condiciones de existencia (de posibilidad) son diferentes, como también lo son sus objetivos, de manera que la forzada relación se diluye.

Desde una perspectiva material, lo que pretendo desarrollar a lo largo de estas páginas es un análisis del testimonio, considerándolo como un cuerpo discursivo, un cuerpo que afecta y es afectado, a su vez, por otros cuerpos (no sólo) discursivos. Para ello, me centro en la filosofía spinozista, la cual considera que un cuerpo debe definirse por su potencia y no por su pertenencia a algún género identitario, ya que éste no sería más que una noción abstracta y confusa. Un cuerpo, nos señala Spinoza (2000) se define por el conjunto de las relaciones que lo componen, las que determinan qué puede hacer dicho cuerpo. En otras palabras, ¿cuál es su potencia? En este sentido, el filósofo holandés, a modo de ejemplo, señala que si bien el caballo de carreras y el caballo de trabajo pertenecen a la misma especie, sus potencias, sin embargo, son diferentes; esto porque el primero estaría más cerca de un galgo y el segundo de un buey. Siguiendo esta línea, pero yendo más allá de la filosofía para instaurarnos en el campo de la literatura (aunque no exclusivamente), la pretendida genealogía de lo que hoy se denomina "narrativa testimonial latinoamericana" no debería buscarse en los discursos producidos durante la colonia, simplemente porque esta NO existe. Por el contrario, dicha narrativa emerge recién durante los años sesenta en América Latina como una especie de discurso de resistencia de los grupos subalternos, dirigido hacia una opinión pública internacional con el fin de denunciar aspectos o acciones que los sectores dominantes ocultan. Es, por ejemplo, el caso de Tejas Verdes (Hernán Valdés, 1996) en Chile o el mismo testimonio de Rigoberta, ambos publicados fuera de sus países de origen, España y Cuba, respectivamente, y cuyos objetivos eran develar las atrocidades que se estaban cometiendo en las dictaduras en las cuales sus países se encontraban. De esta manera, no sólo el contexto, sino también los objetivos hacen de la narrativa testimonial un discurso radicalmente alejado de los textos coloniales señalados más arriba, donde los "sin voz" comienzan a tomar la palabra para convertirla en escritura. Ya no se trata, como diría Martin Lienhard, de un secuestro del discurso indígena; por el contrario, ahora la voz se hace cuerpo y se materializa generalmente mediante una articulación con "inte-
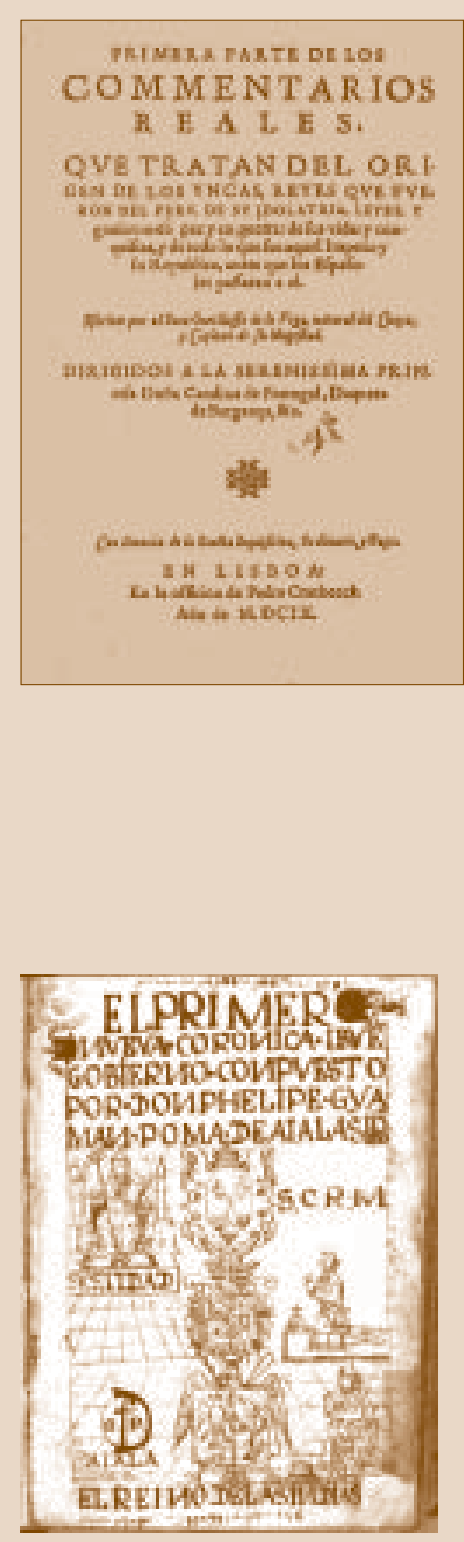


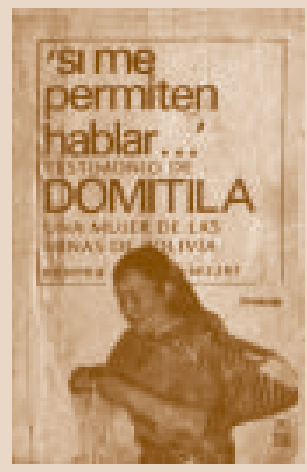

lectuales" comprometidos en los mismos objetivos de develamiento. Pero, uno de los aspectos más importantes de la narrativa testimonial se encuentra en el hecho de que las mujeres indígenas, doblemente subalternizadas por su condición de indígena y mujer, emergen como parte importante en la toma de la palabra (Franco, 1988), que rompe las constricciones del habla, al emerger de los límites de la supervivencia dictatorial.

\section{LA CRÓNICA O EL ARCHIVO DE LAS ELITES}

Para los estudiosos de la Colonia, las crónicas representan una especie de material, una fuente de primera mano para la indagación sobre los acontecimientos que, durante esa época, tuvieron lugar. Comenzando por los viajes hasta los asentamientos, pasando por las exploraciones y los enfrentamientos entre hispanos e indígenas, las crónicas que de estos sucesos representarían una fuente voluntaria capaz de constituir la memoria dominante de las sociedades. En este sentido, la crónica sería “el reflejo del 'imaginario' que los componentes de un grupo construyen, de su mentalidad e ideología", que refleja "el conflicto interno de toda sociedad" (Aróstegui, 1994). Pero la perspectiva imperante en dichos textos no es la de todos los sectores en conflicto, sino más bien la de un sector: el dominante, ya que no cualquier persona estaba en condiciones de redactar una crónica (y menos epístolas). Desde un comienzo, quienes las escribieron fue un restringido grupo de hombres de la fe o la milicia, conquistadores espirituales y territoriales poseedores de un saber letrado. Por tanto, la pluralidad de miradas sobre un acontecimiento acá, como en cualquier otro discurso, se ve restringida hacia la producción de una determinada "historia" por parte de los intereses eclesiásticos o militares, o simplemente por sus miembros individuales. Por otra parte, durante la colonia las elites locales también asirán la letra en favor de sus intereses particulares redactando, tanto en su lengua nativa como foránea, de la misma manera que los criollos o los hispanos.

Me interesa aquí dar cuenta de la ambigüedad en la que se ve envuelta la crónica considerada como antecesora de la narrativa testimonial, producto de una mirada retrospectiva sujeta a la voluntad de fomentar determinadas lecturas desde el presente. Se trataría de un afán por crear puntos de encuentro con los orígenes de la escritura etnográfica, como también con la tradición literaria denominada heterológica, preocupada de vehiculizar la voz del otro en forma de documento. Mercé Picornell Belenguer señala que 
la doble tradició etnográfica y literaria de la qual les cróniques han estat tractades com a precedent no pot menystenir la intencionalitat que subjeu a aquest relats de conquesta, uns relats que no són únicament descriptius, sinó fruti d'una voluntat d'informar, com en el cas de Colom, als qui l'han subvencionat, sobre els recursos mercantils de les zones que "descobreix", i de deixar constrància escritas de les terres conquerides... Un dels llocs comuns del tractament de les cròniques en relació amb els testimoniosés precisament aquest carácter "inaugural" en la representaciò del "nou mòn" (Picornell, 2003:123).

Al respecto, para Mercedes Serna las crónicas de "Indias" recurren a modelos textuales clásicos para describir el "descubrimiento", de la misma manera que se hacía en la tradición medieval con los clásicos paganos que pretendían recordar y transmitir. En las crónicas, por tanto, no habría una separación de la visión dominante de la historia vista como el desarrollo de un proyecto divino imperante incluso después del medioevo.

De ahí que para Picornell Belenguer (2003) quienes se empeñan en defender la crónica como origen de la narrativa testimonial (la búsqueda de una identidad) se apoyan en modalidades discursivas tales como: a) una voluntad documental, b) una forma vivaz de presentar la información y c) la pretensión de originalidad estética en la representación del "nuevo mundo". Carmen Ochando (1998) es una de las personas ubicadas en esta línea, para quien con este tipo de discursos se "rompen los moldes acartonados de la historiografía tradicional e inauguran una nueva manera de narrar la Historia”. Para ella, los

... protagonistas de la Conquista fundaron, con las crónicas, los cimientos de la literatura del Nuevo Continente. Colón, Alonzo de Ercilla, Bartolomé de las Casas, Alvar Núñez Cabeza de Vaca, Pizarro, Cortés, Bernal Díaz del Castillo, y otros, inician, sin intención literaria explícita, los mitos de la literatura latinoamericana, sus ambiciones, su paisaje, sus gustos y sus disgustos... El paisaje, la naturaleza y los propios hombres que encuentran a su paso por las tierras americanas, desbordan las esperanzas de los conquistadores quienes, en su afán de incorporarse en la Historia... deslizarán su asombro en una escritura testimonial y vivificadora, cuyas bases se anclaban en la literatura y pensamiento europeo de la época (citado en Picornell, 2003:125).

Frente a la posición de Ochando, Picornell Belenguer insiste en que no le es posible imaginar tipos de historiografía tradicional que no estén basados en crónicas. Por el contrario, 
crec, més aviant, que volv manifestar la diferència d’una escriptura de la història mès litèraria que la que es deselvoluparia posteriorment, i que, fonamentaria, de fet, la disciplina. D`altra banda, si realment creim que les cròniques inauguren una forma d'explicar la història no podrem deixar [Ochando] de tener en compte que aquest inici està vinculat a l'expansió colonial , així como a la representació de una realitat "alteritzada" que la justifica: la del pobles indígenes que habiten els espais "conquerits" (Picornell, 2003:125).

El asombro volcado en una "escritura testimonial y vivificadora" del que habla Ochando, está marcado no sólo por un "afán de incorporarse en la Historia” (lo cual también es cuestionable), en gran medida también lo está por una voluntad de poder que arrastra en sus hombros destrucción y muerte, todo lo que, por el contrario, lleva a Rigoberta Menchú a lanzarse en el proyecto de un libro que, desde su aparición en 1983, la transformó en uno de los íconos de la resistencia subalterna. En este sentido, la crónica como cuerpo discursivo se distancia radicalmente de la narrativa testimonial, debido fundamentalmente a que esta está inmersa en una empresa de denuncia, una empresa preocupada de mostrar las atrocidades que están experimentado los sectores marginados, donde la tortura y el genocidio, más que las ambiciones personales, devienen una constante de la vida cotidiana. Una equiparación similar a la de Ochando se desprende del argumento de Leonidas Morales, ya que cuando éste habla del testimonio como un discurso "transhistórico", lo que hace es colocar los discursos emergidos desde la subalternidad en el mismo plano que los discursos emanados por "una voz degradada, pervertida, o incluso [de] la voz del poder hegemónico mismo, encubierta o cínicamente expuesta” (1999:171). Sólo una perspectiva elitista pretendería equiparar una narrativa hegemónica con una subalterna. He aquí el problema de la mirada clínica instaurada por el crítico literario, que intenta una operación casi quirúrgica para lograr integrar en un mismo plano (cuerpo) discursos que apuntan a cartografías socio-políticas disímiles, si es que no antagónicas.

Por otra parte, y colocándome un tanto quisquilloso, en tanto enunciado, más que a la narrativa testimonial, la crónica pertenece al plano archivístico descrito por Michel Foucault. El archivo, señala el filósofo francés, no es la acumulación de textos pasados que dan "testimonio" de una determinada identidad, como tampoco lo serían aquellos edificios denominados Archivo Nacional, encargado de

... registrar y conservar los discursos cuya memoria se quiere guardar y cuya libre disposición se quiere mantener. Más bien, es por el contrario 
lo que hace que tantas cosas dichas, por tantos hombres desde hace tantos milenos, no hayan surgido según las leyes del pensamiento, o por el solo juego de las circunstancias, por lo que no son simplemente el señalamiento, al nivel de las actuaciones verbales, de lo que ha podido desarrollarse en el orden del espíritu o en el orden de las cosas; pero que han aparecido gracias a todo un juego de relaciones que caracterizan propiamente el nivel discursivo (2002: 219).

En otras palabras, el archivo es aquello que norma lo que puede, como también aquello que no puede ser hablado o escrito; se trata de lo que determina las condiciones de cada toma de palabra, algo que en las crónicas está más que determinado, ya que en ellas no es posible escribir cualquier cosa ni de cualquier modo, debido, entre otras cosas, a la influencia de la estética medieval en su producción. Por otra parte, la crónica en tanto discurso se ubica entre la langue y la parola, mientras que el testimonio narrado por un sobreviviente se ubica entre la lengua y el archivo como tal. Tal mirada considera los enunciados testimoniales ya no desde el discurso sino desde la lengua, lo que implica tomar en cuenta no lo dicho (y lo no dicho) sino lo decible (y lo no decible); en otras palabras, se trata de considerar tanto la posibilidad como la imposibilidad de generar un enunciado, de que éste tenga lugar. Es en este plano, señala Giorgio Agamben (2002), donde se ubica el cuerpo discursivo testimonial, alejándose por tanto de los discursos coloniales de una manera radical.

\section{EL ARCHIVO INSTITUCIONAL: SOBRE LAS CARTAS Y TESTIMONIOS COLONIALES}

Si bien los "testimonios" coloniales no han sido directamente relacionados a la narrativa testimonial de la misma manera que las crónicas, el uso de la palabra testimonio por parte de la academia obliga a considerarlos de todas maneras. Esta relación se genera debido al significado literal de la palabra "testimonio". De las cinco definiciones que la RAE entrega, tres son, para efecto de nuestros objetivos, necesarios traer a colación: 1) atestación o aseveración de algo; 2) instrumento autorizado por escribano o notario, en que se da fe de un hecho, se traslada total o parcialmente un documento o se le resume por vía de relación y 3) prueba, justificación y comprobación de la certeza o verdad de algo. "Aseverar", "dar fe" y "probar" son los hilos conductores de estas definiciones, donde el tema de la verdad parece ser el eje común a todas. Pero, cuando uno lee los textos académicos dedicados a los 
estudios de la Colonia (o también al periodo prehispánico), la palabra testimonio aparece una y otra vez, pero distanciada de una idea de verdad, por muy general que ésta pueda ser. Además, la definición de testimonio generalmente se da por sobreentendida, generando una ambigüedad conceptual considerable. Observemos, por ejemplo, cómo usa la palabra Serge Gruzinski, en La colonización de lo imaginario (1991).

Tanto la arqueología como la historia prehispánicas han olvidado, frecuentemente, que la mayoría de los testimonios que conservamos de la época precortesiana fueron elaborados y redactados en el contexto trastocado de la naciente Nueva España y que, antes que nada, lo que ofrecen es un reflejo de esa época (1991:10).

La doble naturaleza de las fuentes indígenas del siglo XVI (pintadas y manuscritas) nos lleva a fijarnos en la remodelación y la alteración de las cosas observadas que implica ponerlas por escrito... (1991:10).

Diseminada en México, España, Italia, Francia y Estados Unidos, una documentación considerable permite estudiar a los indios de la Nueva España o, para ser más exactos, captar lo que representaban a los ojos de las autoridades españolas (1991:11).

Por lo demás, estos materiales han dado pie a una historia institucional, demográfica, económica y social de los indios de la Colonia... (1991:11. Las cursivas son mías).

Como es de notar, Gruzinski utiliza la palabra testimonio como sinónimo de fuentes, documentación y materiales. Lo mismo sucede en el texto El destino de la palabra, de Miguel León Portilla, cuando este señala que "los vestigios arqueológicos, en particular las inscripciones y figuras que los acompañan en estelas y pinturas murales, así como unos cuantos libros pictoglifícos son los únicos testimonios incuestionables del pensamiento mesoamericano... Hay ciertamente otros testimonios, pero debe reconocerse que son más tardíos, resultado de varios modos de "trasvase", paso o conversión a otros sistemas de registro" (1996:19). A lo que ambos autores se están refiriendo es a la noción tradicional de "fuentes", sean éstas monumentales, orales, audiovisuales, escritas, o de otro tipo (como los mismos glifos), no siempre ubicables en los Archivos Nacionales (aunque se espera que pronto lo estén para uso académico), pero sí sujetas al registro y a la conservación para el resguardo y/o producción de cierta memoria, y cuya circulación, por tanto, no es abierta. En este sentido, dentro de lo que denomino, a falta de un concepto más preciso, los "testimonio-fuentes coloniales" se incluirían 
desde discursos iconográficos como el Códice Telleriano-Remesis, pasando por discursos mixtos como la crónica de Guaman Poma de Ayala, hasta llegar a las cartas tanto indígenas (no sólo de las elites) como hispanas, pasando por los registros de todos los juicios realizados, incluyendo las crónicas, los manifiestos y petitorios, como también los escritos de Sor Juana o Ciguenza y Góngora, la escritura de monjas exigida por los sacerdotes, los testamentos, etc. En otras palabras, todo "documento" (escrito o no) que se guarda de la colonia es un discurso posible de ser considerado un testimonio-fuente, en el sentido de que nos permitiría investigar características de dicho periodo. Por tanto, se trataría de documentos de archivo (en el sentido literal), cuya posibilidad de existencia (enunciación) y materialidad (enunciado) se la dio el archivo foucaultiano del que emergieron ${ }^{3}$. Por otra parte Martín Lienhard (1992) ha sido una de las personas que más se ha esforzado en dejar constancia de la "presencia" de los sectores marginados en los documentos/fuentes coloniales, aunque también operando dentro de la ambigüedad semántica del testimonio señalada más arriba. Lienhard ha mostrado que la producción de los diversos discursos generados durante la colonia fue producto de largos e intensos procesos de negociación entre los sectores indígenas y las autoridades hispanas y/o criollas, producción catalizada muchas veces por las situaciones de conflicto. Las "zonas de contacto" que describe Mary Pratt cobran plena vigencia en este sentido, ya que se trata de zonas que dan cuenta de los "encuentros" coloniales entre pueblos histórica y geográficamente distanciados, produciéndose relaciones que involucran coerción, desigualdad y conflictos insuperables, que desembocan generalmente en una producción discursiva que intenta dar cuenta de (y construir) un otro, radicalmente diferente.

\section{EL TESTIMONIO COMO LITERATURA DE RESISTENCIA}

Tal como el 12 de octubre de 1492 marcó un hito para el devenir de la historia mundial, el 11 de septiembre de 2001 marcó otro para la política global contemporánea. El atentado terrorista al World Trade Center conmocionó al mundo entero, sobre todo porque las tecnologías modernas nos permi-

\footnotetext{
${ }^{3}$ Acá es necesario señalar que si bien la mayoría de estas fuentes han sido dejadas por las elites, indígenas o españolas, la presencia de los sectores marginados (no sólo de la letra) se puede rastrear de todas maneras en ellas. La subalternidad se ve reflejada, directa o indirectamente ya que, "the subalterns not only developed theis own strategies of resistance but actually helped define and refined [sometimes only with its presence] elite options" (Mallon, 1994: 1494).
}
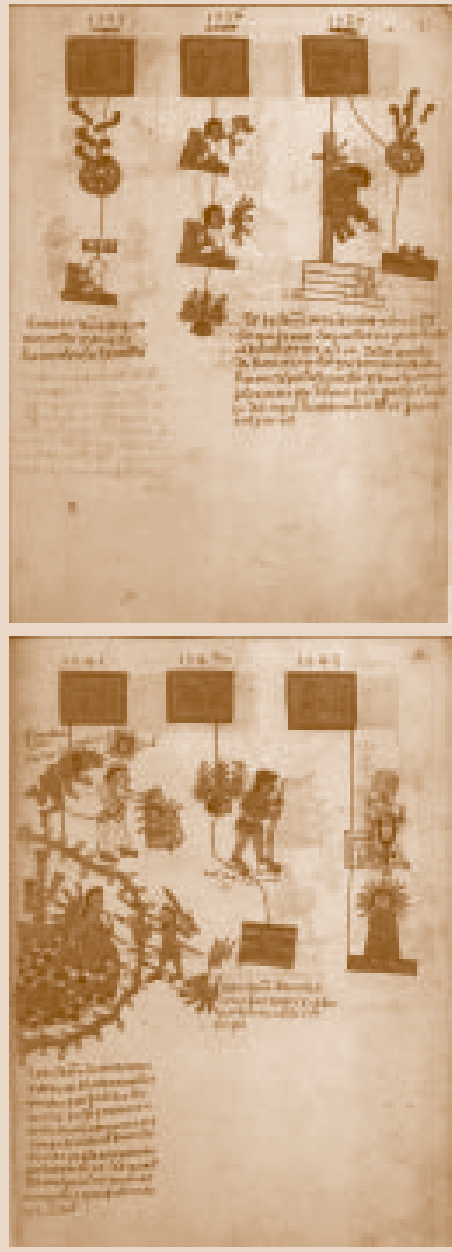
tieron acceder inmediatamente a las horribles imágenes que daban cuenta de una de las acciones más incomprensibles que hemos presenciado últimamente. Durante el año recién pasado vio la luz un texto que recopiló testimonios de latinas y latinos que durante el atentado vivían en Estados Unidos, pero, a diferencia de otros textos testimoniales contemporáneos, estas "voces" fueron incardinadas mediante el correo electrónico (Joysmith y Lomas, 2005). Otro texto similar se produjo en España debido a un atentado terrorista de la misma índole, pero ya no sobre el aire sino sobre el subterráneo. En el prólogo de este libro editado por Varios autores (2004), se señala que el objetivo principal es

... sacar a la superficie algunos trazos de la narración coral -tejida a base de correos electrónicos, sms, imágenes, cuadernos de bitácora o comentarios en weblogs- que fue construyendo otra mirada sobre lo que ocurría aquellos días trágicos y extraordinarios, otro sentido, otra predisposición de ánimo frente a los acontecimientos. Una narración que, lejos de ser un añadido a lo que pasaba producía efectos muy concretos, impulsaba a la acción, desplazaba los imaginarios más allá de cualquier anteojera mediática, daba forma a lo que se veía y vivía entonces, lanzaba mensajes de rebeldía en botellas digitales para otras personas en búsqueda, escépticas frente a la versión oficial.

Como se puede apreciar, los contextos y las condiciones de posibilidad para la emergencia de discursos que intentan dar cuenta de determinados hechos es muy disímil, como lo es el archivo foucaultiano que los produce. Lo que acá denominamos literatura de resistencia emerge en el contexto latinoamericano de los años sesenta, del cual el texto de Rigoberta Menchú es el más conocido y prácticamente ha sido elevado al nivel de paradigma de este tipo de discursos, distanciándose tanto de los discursos coloniales como de los discursos mediáticos contemporáneos. Como es ya sabido, la "canonización" del testimonio se produce en 1970, cuando Casa de las Américas decide entregar un premio a la narrativa testimonial. La revista de Casa publicó en 1995 una serie de documentos que describen detalladamente la discusión (del jurado de 1969) que dio origen al premio conocido hoy como Testimonio Latinoamericano. En aquella discusión participó Ángel Rama, quien señaló lo siguiente:

[...] Hay una cosa importante [...] que es lo siguiente. Yo no sé la experiencia que tienen los demás jurados, pero sí la que tuvimos nosotros en el campo de la novela. Existen, entre otras buenas obras literarias, con interés, que no todas llegan a la calidad de un premio que podríamos 
mencionar, pero cuyo valor no está solamente en lo literario, sino en lo que testimonian del proceso de la América Latina.

Entonces yo voy a sugerir una cosa, voy a sugerir a todos los jurados si nosotros podemos proponerle a la Casa que cree, que establezca una colección que se llame Testimonio Latinoamericano; es decir, una colección en la cual una novela, un ensayo, la poesía, el cuento, dé testimonio de lo que está pasando en la América Latina y de lo que se está realizando (1995:122).

Este dar testimonio del que habla Ángel Rama podría ser leído de la misma manera que las fuentes, pero, dada las condiciones de posibilidad y el contexto de la narrativa testimonial, se distancia radicalmente por encontrarse dicho discurso ubicado no entre la palabra y la lengua, sino, como vimos más arriba, entre ésta y el archivo foucaultiano como tal. El testimonio al que me estoy refiriendo tiene como característica central el ser narrado (oral o escrituralmente) por un sobreviviente, una persona que tiene la posibilidad de contar el horror que ha vivido y al que ha sobrevivido. No se trata de un testigo en tercera persona, sino alguien que ha experienciado en carne propia lo que cuenta, y que en dicha experiencia traumática ha perdido amigos, familiares y personas con las que compartió la violencia, la opresión y la tortura, de manera que estar vivo para contarlo es una (enorme) posibilidad, que hace de quienes se deciden a hablar "historiadores combativos", como les llama Primo Levi (2002). Se trata de hablar por aquellos que ya no están o simplemente no pueden hacerlo, de hablar por delegación. Giorgio Agamben es quien ha reflexionado sobre este hecho, al señalar que “... testimoniar significa ponerse en relación con la propia lengua en la situación de los que la han perdido, instalarse en una lengua viva como si estuviera muerta o en una lengua muerta como si estuviera viva, más en cualquier caso, fuera tanto del archivo como del corpus de lo ya dicho" (2002:169). En otras palabras, se trata de que en el testimonio se tiene efectivamente la posibilidad de no poder dar cuenta, ya que la situación de la que viene el testimoniante es, como dice el filósofo italiano, la de un contexto biopolítico, donde, más que hacer vivir (régimen capitalista) o hacer morir (régimen soberano), se trata de hacer sobrevivir; un contexto biopolítico que realiza una escisión que separa a aquellas personas cuya humanidad es puesta en duda (debido a su estadía en un campo de concentración), de aquellas que pueden testimoniar. El testimonio se da, entonces, sólo como contingencia, existe sólo mediante la posibilidad de no tener lugar. De ahí que la relación entre al archivo y la lengua necesite de un sujeto que dé cuenta, "en la posibilidad misma de hablar, una imposibilidad de palabra. 


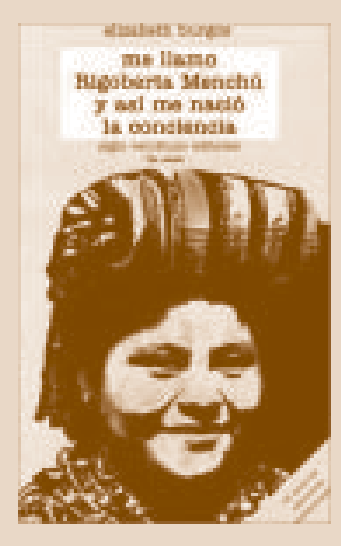

Por eso se presenta como testigo y puede hablar por aquellos que no pueden hacerlo". En este sentido, M ellamo Rigoberta M enchú es un testimonio "que adquiere realidad mediante una impotencia de decir, y una imposibilidad que cobra existencia mediante una posibilidad de hablar... [su] testimonio es esta intimidad indivisible" (Agamben, 2002:153). En otras palabras, es la impotencia (de decir) que se presenta en los sobrevivientes lo que permite la aparición del testimonio como una potencia, potencia de la que no se desprende, como en el caso de las fuentes, la posibilidad de una búsqueda verídica de los hechos que se narran en su contenido; por el contrario, el testimonio es la insubordinación del custodiado archivo, de manera que ya no es posible fijarlo en él. Por ello, en cuanto existencia de la lengua, el testimonio no se resta ni a la memoria ni al olvido, por el contrario, se resiste "en nombre de un no poder decir" (Agamben, 2002:165).

Pero el hecho de que el testimonio se resista a ser custodiado y, por tanto, a ser tratado como fuente, no se sustrae al intento de quienes intenten hacerlo. Es el caso de un antropólogo estadounidense, David Stoll (1999), quien ha cuestionado el testimonio de Rigoberta Menchú, señalando que algunas partes del libro son problemáticas ${ }^{4}$. Del libro de Stoll se desprende que los hechos deben ser contrastados empíricamente y recogidos mediante la metodología correcta, de manera que el testimonio debe, por tanto, ser analizado con las técnicas objetivas pertinentes. Sin embargo, John Beverley (1999) ha señalado que el problema de la veracidad no ha sido lo más importante para Stoll, ya que éste no cuestiona la mayor parte de los acontecimientos narrados por Rigoberta; por el contrario, este antropólogo está comprometido con develar los -negativos- usos del texto de Menchú por parte de la izquierda intelectual estadounidense y los grupos de solidaridad internacionales con la guerrilla en Guatemala, que también se han articulado y simpatizan, por ejemplo, con el EZLN en México. Para Beverley, "la cuestión de la verdad está subordinada al desacuerdo ideológico de Stoll con la estrategia de la lucha armada". Stoll señala que en el trabajo de campo no es difícil encontrar a alguien que nos cuente lo que queremos escuchar, de manera que si su libro se basa en entrevistas realizadas por él años más tarde a indígenas guatemaltecos, éstos no tendrían por qué tener más credibilidad que Menchú. Esto siguiendo su misma lógica, nos señala Beverley.

Finalmente, el texto de Menchú nos (de)muestra cómo la narrativa testimonial se distancia radicalmente, tanto de los discursos de la colonia, como

\footnotetext{
${ }^{4}$ El libro de Stoll sólo ha sido traducido al español y publicado sólo en una página web. Ver: http://www.nodulo.org/bib/stoll/rmg.htm
} 
de los géneros referenciales más contemporáneos. Más que su identidad, es su potencia de enunciar, precisamente mediante la imposibilidad de hacerlo que se le presenta al testigo, donde estriba su particularidad y su capacidad de afectar el espacio sociopolítico. En el caso de Centroamérica, la necesidad de comunicar una situación de urgencia es la que ha catalizado la literatura de este tipo, y la articulación transnacional empeñada en la conformación de un bloque que aspire a lograr, como en el caso de Guatemala, hegemonía allí donde los marginados son la mayoría. Se trata de una articulación que interpela directamente al mundo académico que, más allá de Stoll, ha tenido que lidiar con aquellos sectores intelectuales que ven al testimonio como un "parásito" de los discursos genéricos existentes (Morales), característica similar otorgada al testimonio por el neoconservador Dinesh D Souza, uno de los críticos más acérrimos del multiculturalismo. El testimonio, como literatura de resistencia y develación, nos obliga tanto en la academia como fuera de ella, a tomar posiciones: ya sea para articularnos con los sectores subalternos (no representarlos) o a contribuir a su marginación.

\section{REFERENCIAS}

Agamben, Giorgio. 2002. Lo que queda deAuschwitz. El archivo y el testigo. Valencia: Editorial Pre-Textos.

Aróstegui, Julio. 1994. La investigación histórica: teoría y método. Barcelona: Editorial Crítica.

Beverley, John. 1999. Subalternidad y representación. D ebates en teoría cultural. Madrid/ Frankfurt: Vervuert, Editorial Iberoamericana .

Burgos-Debray, Elizabeth. 1994. Me llamo Rigoberta M enchú y así me nació la conciencia. México, D.F.: Editorial Siglo XXI.

Colom, Yolanda. 2000. M ujeres en la alborada. Guerrilla y participación femenina en Guatemala, 1973-1978. Guatemala: Editorial Artemis-Edinter.

Cusi Yupanqui, Titu. 1973. Relación dela conquista del Perú. Lima: Ediciones de la Biblioteca Universitaria.

De Sahagún, Bernardino. 1981. El M éxico antiguo. Caracas: Editorial Biblioteca de Ayacucho.

Díaz del Castillo, Bernal. 1983. Historia verdadera de la conquista de la Nueva España. México: Editorial Porrúa.

Escudos, Jacinta. 1987. Apuntes de una historia de amor que no fue. San Salvador: Editorial UCA.

Foucault, Michel. 2002. La arqueología del saber. Buenos Aires: Editorial Siglo XXI. 
Franco, Jean. 1988. "Si me permiten hablar: la lucha por el poder interpretativo", en Casa de las Américas, 174, pp. 88-94.

Garcilazo de la Vega, Inca. 1999. Comentarios reales. Madrid/Frankfurt: Editorial Iberoamericana/Vervuert.

Gruzinski, Serge. 1991. La colonización de lo imaginario. México, D.F.: Editorial Fondo de Cultura Económica.

Guaman Poma de Ayala, Felipe. 1980. El primer Nueva crónica y buen gobierno. México. D.F.: Editorial Siglo Veintiuno.

Joysmith, Claire y Clara Lomas. 2005. One Wound for Another-U na herida por otra: testimonios delatin@sin theU.S. through Cyberspace (11 deseptiembre de 2001-11 de marzo de 2002). México D.F.: Editorial CISAN/Colorado College.

Levi, Primo. 2002. Los hundidos y los salvados. Barcelona: El Aleph Editores.

León Portilla, Miguel. 1996. El destino dela palabra. México, D.F.: Editorial Fondo de Cultura Económica.

Lienhard, Martin. 1992. Testimonios, cartas y manifiestosindígenas (D esdela conquista hasta comienzos del siglo XX). Caracas: Editorial Biblioteca Ayacucho.

Mallon, Florencia. 1994. "The Promise and Dilemma of Subaltern Studies", en American Historical Review, 99(5), pp. 1491-1515.

Morales, Leonidas. 1999. "Género y discurso: el problema del testimonio", en Mapocho, 46, pp. 167-176.

Núñez Cabeza de Vaca, Alvar. 2001. Naufragios. Madrid: Editorial Alianza.

Ochando, Carmen. 1998. La memoria en el espejo. A proximación a la literatura testimonial. Barcelona: Editorial Anthropos.

Picornell Belenguer, Mercé. 2003. Testimoni i etnoficció. Poètica i política de la representatió de la veu subalterna. Tesis para obtener el grado de Doctorado en Teoría de la literatura i literatures comparades, Departament de Filología Espanyola, Universitat Autónoma de Barcelona, Barcelona.

Pratt, Mary Louis. 1997. O jos imperiales: literatura de viajes y transculturación. Buenos Aires: Editorial Universidad Nacional de Quilmes.

Rama, Angel. 1995. "Conversación en torno al testimonio", en Casa delas Amé ricas, 200, pp. 122-123.

Spinoza, Baruch. 2000. Ética. Madrid: Editorial Trotta.

Stoll, David. 1999. Rigoberta M enchú and the Story of All Poor Guatemalans. Colorado: Westview Press.

Tula, María Teresa. 1994. M aría Teresa Tula, Human Rights Activist of El Salvador. Cambridge: South End Press.

Varios autores. 2004. Pásalo! Relatosy análisissobreel 11-M y los díasquesiguie ron. Madrid: Editorial Traficantes de Sueños.

Viezzer, Moema. 1988. "Si me permiten hablar..." testimonio de Domitila, una mujer de las minas de Bolivia. México, D.F.: Editorial Siglo XXI.

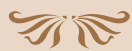

